\title{
The influence of the nucleus pulposus on the stress distribution in the natural and prosthetic intervertebral disc
}

\author{
Robert Karpiński ${ }^{1,{ }^{*}}$, Łukasz Jaworski ${ }^{2}$, Józef Jonak ${ }^{1}$, and Przemysław Krakowski ${ }^{3}$ \\ ${ }^{1}$ Lublin University of Technology, Faculty of Mechanical Engineering, Department of Machine Design and Mechatronics, \\ Nadbystrzycka 36, 20-618, Lublin, Poland \\ ${ }^{2}$ Independent researcher, Lublin, Poland \\ ${ }^{3}$ Orthopaedic Department, Łęczna Hospital, Krasnystawska 52, 21-010 Łęczna, Poland
}

\begin{abstract}
The aim of this article was to present the results of a preliminary study on the stress distribution in the lumbar intervertebral disc [IVD] under loads induced during daily activities. Basic anatomy, biomechanical analysis of the vertebra and intervertebral disc were introduced. The third and fourth lumbar vertebrae were chosen for the study because they carry considerably higher loads, especially while standing or sitting. The static mechanical analyses using the finite element method (FEM) were conducted for four standard loads reflecting patient's positions: recumbent, standing, sitting and standing with additional loads, and three models: an intervertebral disc with an inner nucleus pulposus and two prosthetic intervertebral discs, with or without an artificial nucleus. The FEM analysis was performed in the SolidWorks Simulation module on reverse-engineered 3D models of vertebrae and the intervertebral disc, based on a series of computed tomography [CT] scans of the patient's spine, which had been properly processed in Materialise Mimics software and exported to CAD files. The model of the fourth intervertebral disc, placed between third and fourth vertebra, had been additionally modified to include its inner core, the nucleus pulposus.
\end{abstract}

\section{Introduction}

Back pain is one of the most common reasons for orthopaedic diagnosis and treatment. It is a prevalent health problem, and one of the leading causes of disability [1]. The mechanism of back pain development is highly complex. However, it is believed that in most of the cases the disease of intervertebral disc is involved in back pain. Moreover, sparse infiltration of intervertebral discs by blood vessels in adults [2], is responsible for very limited capacity for healing of affected disc. Therefore, prevention of disc diseases and, if necessary, adequate treatment is essential for health preservation. Furthermore, thanks to the development of new research methods in medicine, some degenerative diseases can be detected and treated before worsening the overall health of the patient $[3,4]$. The movement patterns of lumbar spine were investigated in the past; however, the exact mechanisms are not yet fully understood.

The aim of this study is to determine the effect of the nucleus pulposus on stress distribution in normal intervertebral disc and two variants of intervertebral discs prosthetic implants: with and without the prosthetic nucleus. FEM simulations are conducted for four standard loads reflecting the following positions of the patient: recumbent (70 \% body weight $[\mathrm{BW}])$, standing
$(100 \% \mathrm{BW})$, sitting $(140 \% \mathrm{BW})$, and standing with additional load (300\% BW).

\section{Anatomy and biomechanics of human spine}

Spine is a complex axial structure, which is responsible for carrying loads, body movement and protection of nerve roots. As proposed by Panjabi, it is composed of three interdependent components: passive and active musculoskeletal systems, and neural system [5-7]. Active musculoskeletal system is composed of muscles and their tendons surrounding vertebral column. Passive musculoskeletal system is composed of vertebrae, intervertebral discs and ligaments of the spine. The neural component of the spine, which is created by nerve endings, is widely diffused around ligaments, muscles and tendons of the spine. Such construction enables fluent movement of the human body, while maintaining vertical position of the body. Vertebral column is usually composed of 33 vertebrae, out of which 24 vertebrae including 7 cervical, 12 thoracic and 5 lumbar are independent vertebrae, while 5 sacral and 4 coccygeal are fused together [8]. However, vertebrae are mostly considered as functional spinal units (FSU) [9]. Moreover, the relation between pelvis and lumbar spine is of importance for whole spine biomechanics and potential health problems [6, 7].

*Corresponding author: r.karpinski@pollub.pl 


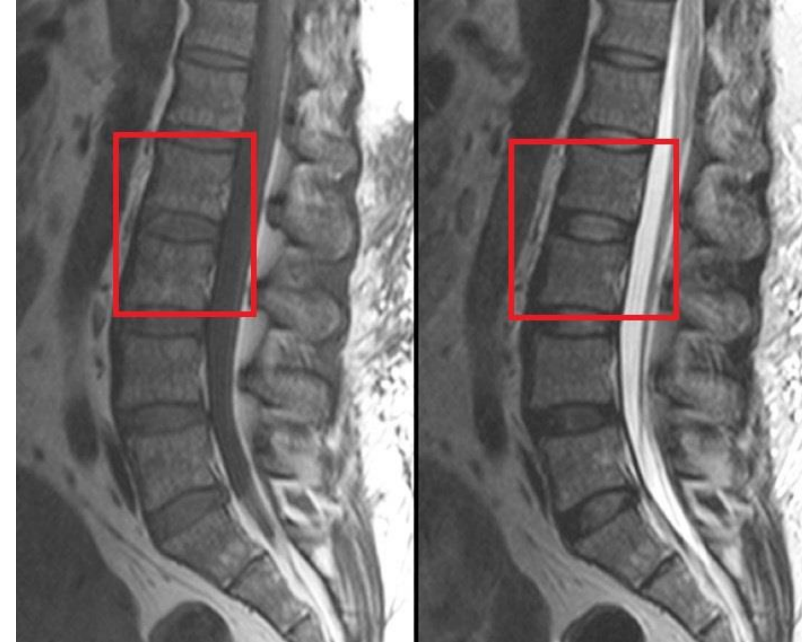

Fig. 1. Magnetic resonance of FSU.

Each FSU (Fig. 1.) is composed of two adjacent vertebrae, intervertebral disc ligaments and muscles surrounding the vertebrae. Each region of the spine has its unique tasks and is specifically designed for this purpose. Vertebrae differ significantly among different anatomical regions. The lower vertebrae and FSU, the greater loads are transmitted and vertebral body as a result of that becomes larger in every dimension. The width of the end plate increases from $15 \mathrm{~mm}$ at $\mathrm{C} 3$ level up to $22 \mathrm{~mm}$ at C7 [12]. Also the depth of the end plate is increasing from $15 \mathrm{~mm}$ up to $18 \mathrm{~mm}$ at the same levels [12]. Similar increase in vertebral body size can be found in thoracic spine. Upper and lower end plates were found to have 3.2 to 2.7 times larger area [13]. Moreover, the increase was found to be linear [13]. The lumbar spine is subjected to the highest loads to be transmitted. Therefore, body of lumbar vertebrae has the greatest contact area. The true vertebrae articulate through joint between facets of articular processes and joints of the vertebral bodies. Joints created between vertebral bodies are mainly responsible for transmitting loads. Each vertebral body articulates through intervertebral discs. They account for $25 \%$ to $33 \%$ of spine length. Each disc consist of three major components which are: nucleus pulposus (NP), which is the most inner part of the disc, the outer layer which is called annulus fibrosus (AF) and cartilaginous endplates which connect the disc with adjacent vertebrae [14]. The inner NP is mostly responsible for strength and flexibility of the spine. The main component of the NP is water which makes up to

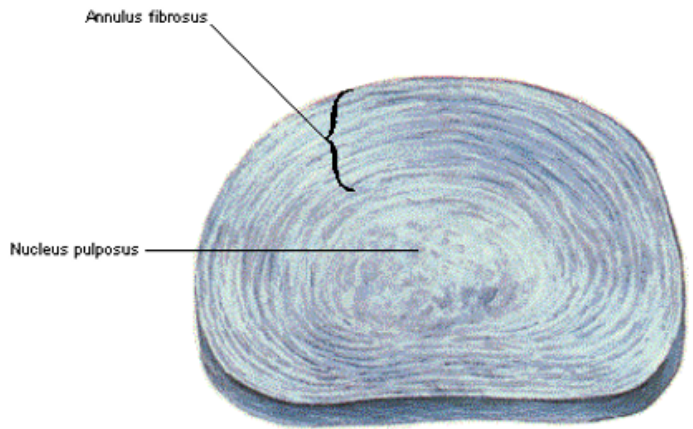

$86 \%$ of the NP mass [15]. Most of the dry mass of the NP is created by proteoglycans, collagen type II and elastin fibres [16]. Moreover, the concentration of proteoglycans is dropping towards the outer regions of the NP. The outer layer of the intervertebral disc is the annulus fibrosus, which encloses the NP in a circular manner. The AF consists of type I collagen fibres which are aligned approximately $30^{0}$ with respect to the transverse plane of the endplates [17]. Collagen fibres are separated by lamellae filled with proteoglycan-rich gel [17]. The true connection between discs and vertebrae is achieved by cartilaginous endplates, which cover the NP and the most inner part of the AF. Endplates take part in equal distribution of loads transmitted by intervertebral disc [18]. The most outer part of annulus fibrosus is connected directly to adjacent vertebrae through collagen fibres. Due to its unique properties, the intervertebral disc is of great importance in degenerative disease of the spine. The loads transmitted by facet joints increase by $85 \%$ in absence of the NP [19] in lumbar spine as a result of which degenerative changes occur. During the load transmission the intervertebral discs are responsible for spine flexibility and mobility. The accumulated load in lumbar spine is highly dependable on posture. It was shown that loads of $60 \%$ of body weight in standing position can rise up to $250 \%$ of body weight in $20^{\circ}$ of flexion and up to $300 \%$ body weight while holding 20 $\mathrm{kg}$ weight in standing position [20]. However, movement of the spine is a combination of direct and indirect loading. At the same time, during flexion of the spine, the intervertebral disc will be submitted to compression, tension and shear forces [21]. Therefore, mechanical properties of the intervertebral disc are widely studied in order to understand the causes of disc failure and to create treatment for the degenerative and traumatic disc derangement $[18,19]$.

\section{Methodology of the study}

Based on a series of computed tomography scans, which were imported to DICOM file format to Materialise MIMICS software, it was possible to calculate a 3D geometry of a third and fourth lumbar vertebra. As a result of an insufficient quality of received scans, the preliminary models were not suited for further analyses; hence a necessity of further processing arose, which was conducted in Materialise 3-matic software, directly connected to MIMICS, and providing control over the parameters of a 3D model, e.g. a number of triangles, and enabling an extended range of operations on given model, e.g. smoothing and stitching surfaces or reducing triangles with a preservation of quality [24-28]. Processed models were ready for importing to STEP file format to Dassault Systemes Solidworks CAD software. 3D files were merged into an assembly comprising of third lumbar vertebra, third lumbar intervertebral disc and fourth lumbar vertebra. For two cases an additional cavern in the IVD was made in order to place an anatomically valid representation of the nucleus pulposus (NP).

Fig. 2. Lumbar intervertebral disc [18]. 


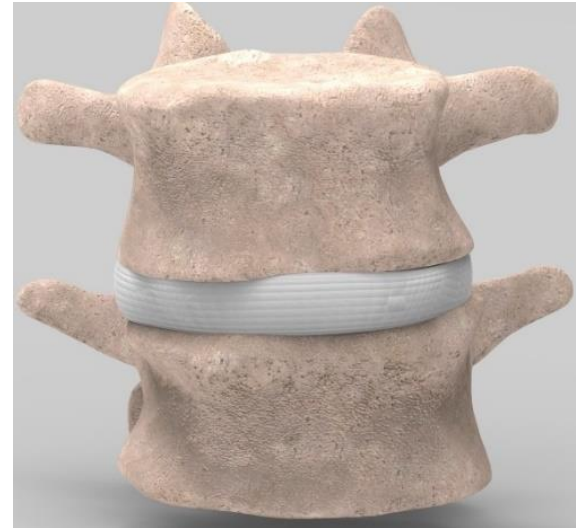

Fig. 3. A render of $3 \mathrm{rd}$ and 4 th lumbar vertebrae with prosthetic intervertebral disc.

Obtained models were then subjected to preliminary analyses using finite element method in Solidworks Simulation module.

\subsection{FEA method}

Finite Element Analysis (FEA) is one of the basic methods of conducting engineering calculations. Its main principle is a division of a geometric model into finite elements, which effects in creating a discrete geometric model, split in simple-shaped subareas, called the finite elements [29, 30]. During calculations, with the use of FEA other physical quantities, such as loads, tensions, restraints are being digitised as well. After conversion the analysis begins, leading to a process of uniting mentioned individual elements as a whole using equilibrium conditions and displacement compatibilities. This step results in an acquisition of algebraic, simultaneous equations, posing as mathematical description of analysed problem. Afterwards, these equations are being solved using values of equilibrium conditions, and their outcome used to compute sought quantities, i.e. tensions [31, 32].

\subsection{Settings}

In order to achieve credible results, materials were assigned to each element. Although metal biomaterials present high mechanical properties, unassisted metal alloys are used mostly in dental surgery [33], while in orthopaedics, particularly in prosthetic intervertebral disc, they cooperate with various plastic materials, such as UHMWPE used in our research. Properties of materials are presented in Table 1. For achieving the best coherence with anatomical structure, the model was then constrained on the bottom surface of the fourth vertebra; then connecting pairs between vertebrae and intervertebral disc were established.

The force acting on the system was applied on the upper surface of the third vertebra, and was equal to 70 , 100,140 and $300 \%$ of body weight, which were induced in following positions of the patient: recumbent, standing, sitting and standing with an additional 196,2N (approx. 20kg) load, with the weight set at $785 \mathrm{~N}$ (approx. $80 \mathrm{~kg}$ ).
Table 1. Properties of materials [31, 34, 35].

\begin{tabular}{|c|c|c|c|c|}
\hline Material & Element & $\begin{array}{c}\text { Young } \\
\text { modulus } \\
{[\mathrm{MPa}]}\end{array}$ & $\begin{array}{c}\text { Poisson's } \\
\text { ratio [-] }\end{array}$ & $\begin{array}{c}\text { Density } \\
{[\mathrm{kg} / \mathrm{m} 3]}\end{array}$ \\
\hline $\begin{array}{c}\text { Trabecular } \\
\text { bone }\end{array}$ & Vertebra & 100 & 0,2 & 297 \\
\hline $\begin{array}{c}\text { Annulus } \\
\text { fibrosus }\end{array}$ & IVD & 50 & 0,45 & 300 \\
\hline $\begin{array}{c}\text { Nucleus } \\
\text { pulposus }\end{array}$ & IVD & 1 & 0,499 & 150 \\
\hline UHMWPE & $\begin{array}{c}\text { Prosthetic } \\
\text { IVD }\end{array}$ & 1070 & 0,41 & 950 \\
\hline
\end{tabular}

Given the complexity of introduced models, it was crucial to generate a sufficient mesh grid. The complete mesh grid was based on curvatures in the model and contained over 230,000 nodes and 160,000 elements, with size between 1.7 and $8.5 \mathrm{~mm}$.

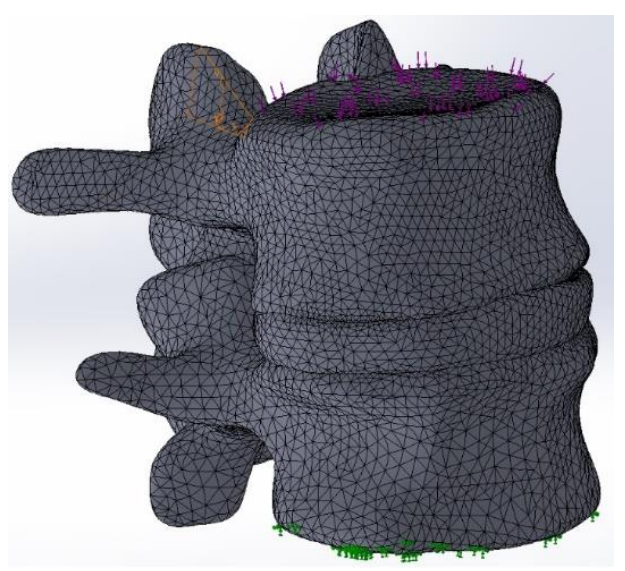

Fig. 4. The constrained model with applied forces.

\subsection{Results}

Conducted analyses resulted in obtaining maps of stress distribution in analysed structures. Samples of these maps are shown in Fig. $5-9$ and contain results for IVD's annulus fibrosus and nucleus pulposus, as well as for their prosthetic counterparts. Maximum values of stress induced in these structures are shown in Table 2.

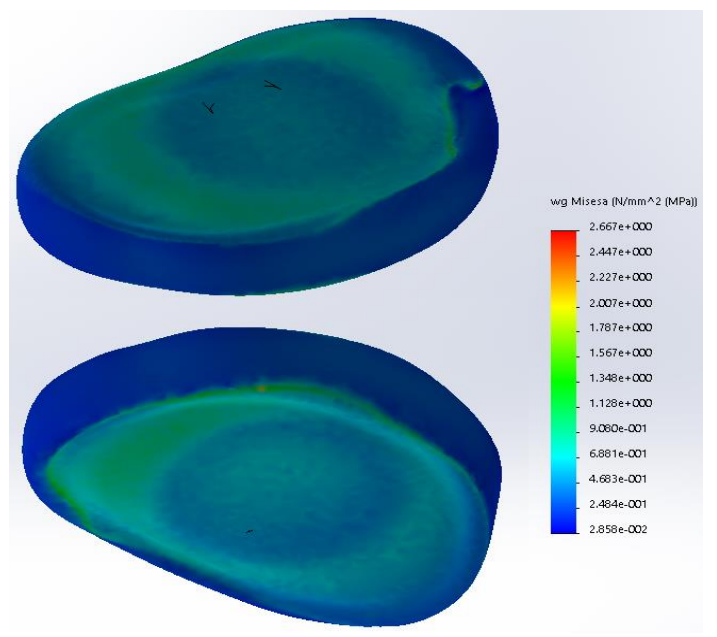

Fig. 5. Stress distribution on upper and bottom surface of IVD for $100 \% \mathrm{BW}$. 


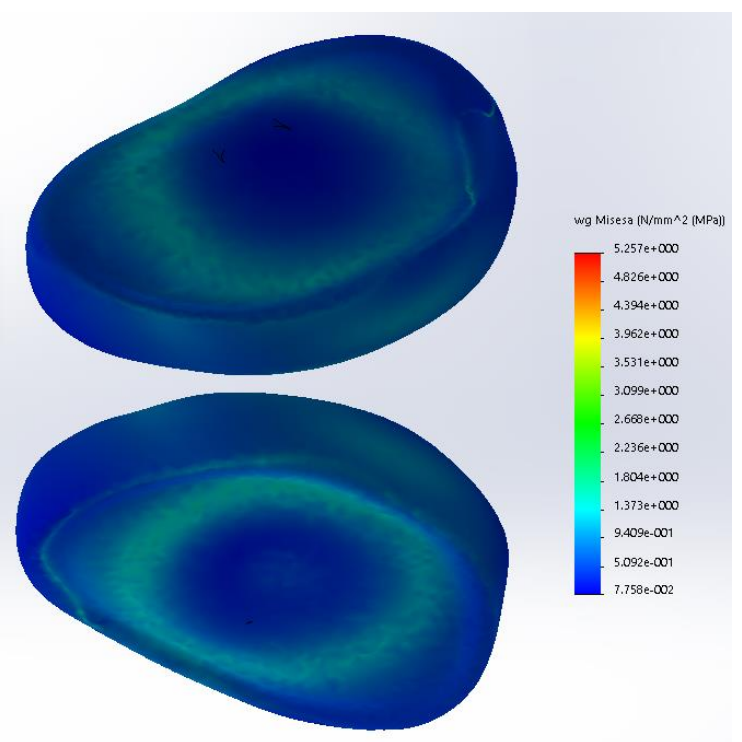

Fig. 6. Stress distribution on upper and bottom surface of prosthetic disc with nucleus for $100 \% \mathrm{BW}$.

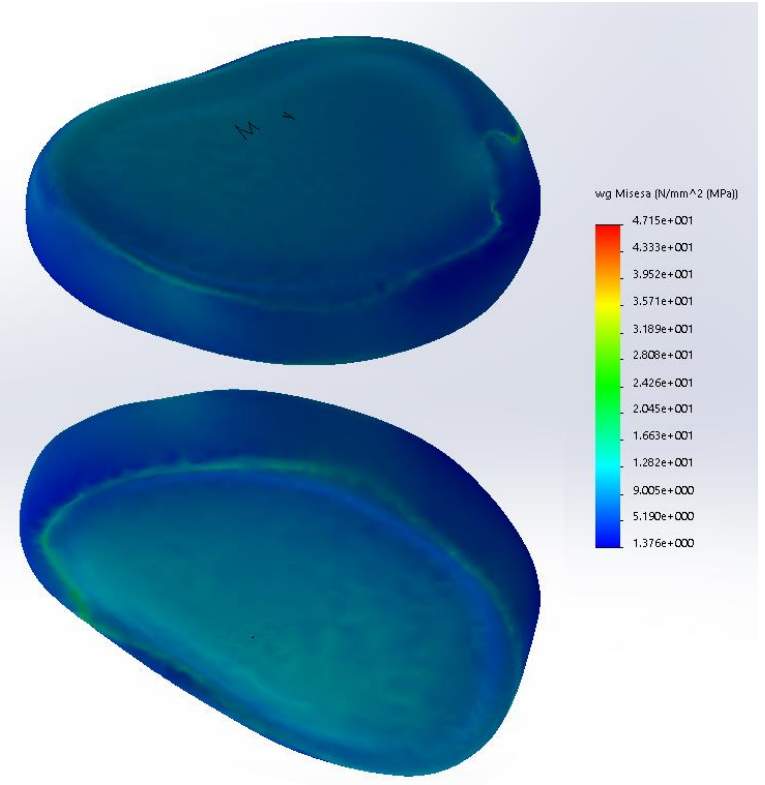

Fig. 7. Stress distribution on the upper and bottom surface of prosthetic disc without nucleus for $100 \% \mathrm{BW}$.

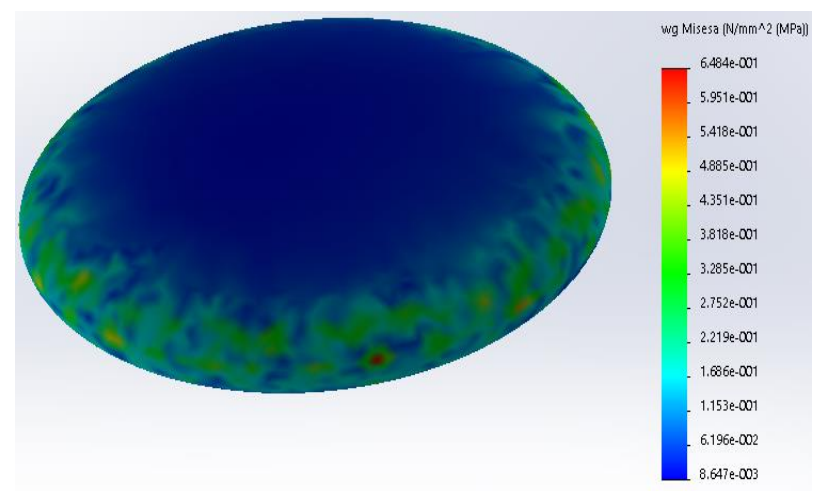

Fig. 8. Stress distribution on the surface of NP for $100 \% \mathrm{BW}$.

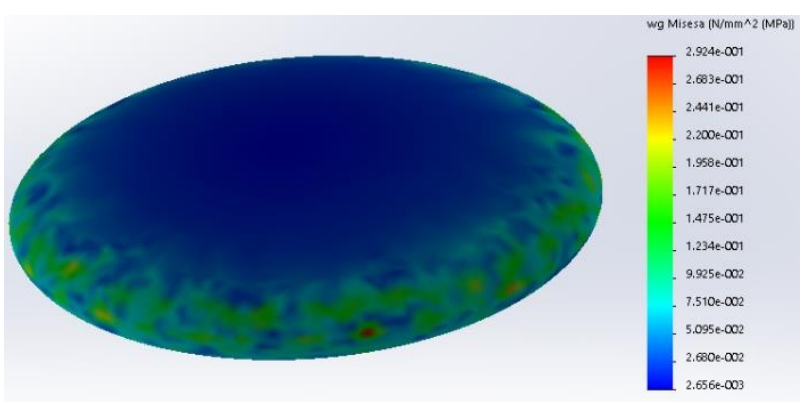

Fig. 9. Stress distribution on the surface of prosthetic nucleus for $100 \% \mathrm{BW}$.

Table 2. Maximum values of stress for conducted analyses.

\begin{tabular}{|c|c|c|c|c|c|}
\hline \multirow[t]{2}{*}{ Model } & \multirow[t]{2}{*}{ Structure } & \multicolumn{4}{|c|}{$\begin{array}{c}\text { Max. stress induced in structure } \\
{[\mathrm{MPa}]}\end{array}$} \\
\hline & & $\begin{array}{c}70 \\
\% \mathrm{BW}\end{array}$ & $\begin{array}{c}100 \\
\% \mathrm{BW}\end{array}$ & $\begin{array}{c}140 \\
\% B W\end{array}$ & $\begin{array}{c}300 \\
\% \mathrm{BW}\end{array}$ \\
\hline \multirow[b]{2}{*}{ IVD } & AF & 1,97 & 2,67 & 3,73 & 8,00 \\
\hline & NP & $\begin{array}{r}4,86 \\
10^{-1}\end{array}$ & $\begin{array}{c}6,48 \\
10^{-1}\end{array}$ & $\begin{array}{c}9,08 \cdot \\
10^{-1}\end{array}$ & 1,95 \\
\hline $\begin{array}{c}\text { Prosthesis } \\
\text { without } \\
\text { NP } \\
\end{array}$ & Disc & $\begin{array}{r}3,30 \\
10^{1}\end{array}$ & $\begin{array}{r}4,76 \\
10^{1}\end{array}$ & $\begin{array}{r}6,23 \\
10^{1}\end{array}$ & $\begin{array}{r}1,41 \\
10^{2}\end{array}$ \\
\hline \multirow{2}{*}{$\begin{array}{l}\text { Prosthesis } \\
\text { with NP }\end{array}$} & Disc & 3,68 & 5,26 & 7,36 & $\begin{array}{r}1,58 \\
10^{1}\end{array}$ \\
\hline & Nucleus & $\begin{array}{c}2,05 \\
10^{-1}\end{array}$ & $\begin{array}{c}2,92 \\
10^{-1}\end{array}$ & $\begin{array}{r}4.09 \\
10^{-1}\end{array}$ & $\begin{array}{c}8,77 \\
10^{-1}\end{array}$ \\
\hline
\end{tabular}

It can be seen, that without the nucleus, neither natural nor prosthetic, stress is distributed almost evenly on contact surfaces of the prosthetic disc. An addition of the nucleus causes more directed distribution, with an accumulation in areas coinciding with the edges of the nucleus.

In case of natural IVD, forces seem to be spreading radially from the nucleus, which could indicate, that less stress is generated in deeper parts of the IVD, therefore increasing its durability.

Differences between maximum values of stress induced in prosthesis without nucleus reach almost 20 times the value of stress for IVD. Results for prosthesis with nucleus, being just twice the discussed value for IVD, may indicate, that the role of nucleus pulposus is crucial for improving durability of prosthetic discs as a result of more efficient distribution of forces acting on the implant. However, the properties of current materials used in manufacturing these types of implants still do not match those of natural, anatomical structures.

\section{Conclusions}

The objective of this paper was to determine the effect of the nucleus pulposus on the stress distribution in a normal intervertebral disc. Two variants of intervertebral prosthetic implants: with and without the prosthetic nucleus were considered. Static FEM simulations were conducted for four standard loads reflecting the following positions of the patient: recumbent, standing, sitting and standing with additional load.

Both, the intervertebral disc model and its prosthesis were developed using reverse engineering based on the 
dimensions obtained from CT scans of the lumbar spine of the patient.

The results of static finite element analysis demonstrate that maximum values of stress induced for prosthesis without nucleus is almost 20 times higher than stress induced for normal intervertebral disc. The difference in maximum values of stress induced between the normal intervertebral disc and the prosthesis with the nucleus pulposus is not so considerable, the stresses in the prosthesis are about two times greater. The results of the finite element analysis indicate that both solutions proposed in this document for the intervertebral disc prosthesis can withstand the loads generated during everyday activities. The maximum stress on the elements is well below the yield point of the material tested, however the maximum stress values are much lower for the prosthesis with the atherosclerotic nucleus, which shows the superiority of this solution. The results of analyses show that even the use of a prosthesis with a nucleus pulposus does not accurately reproduce the mechanics of a normal anatomical intervertebral disc. Therefore, prophylaxis of intervertebral disc lesions is of crucial importance and medical and engineering society should cooperate in order to fully understand mechanics of the spine.

\section{References}

1. D. Hoy, L. March, P. Brooks, F. Blyth, A. Woolf, C. Bain, G. Williams, E. Smith, T. Vos, J. Barendregt, C. Murray, R. Burstein, R. Buchbinder, Annals of the Rheumatic Diseases. 73, 968-974 (2014)

2. M. Rudert, B. Tillmann, Acta Orthop Scand. 64, 37-40 (1993)

3. P. Krukow, K. Jonak, H. Karakuła-Juchnowicz, A. Podkowiński, K. Jonak, M. Borys, M. Harciarek, Psychiatry Research: Neuroimaging. 275, 28-35 (2018)

4. P. Krukow, H. Karakuła-Juchnowicz, D. Juchnowicz, J. Morylowska-Topolska, M. Flis, K. Jonak, Nordic Journal of Psychiatry. 71, 33-41 (2017)

5. M. M. Panjabi, Journal of Spinal Disorders. 5, 383-389 (1992)

6. R. Karpiński, Ł. Jaworski, M. Szala, M. Mańko, ITM Web Conf. 15, 07006 (2017)

7. E. Kozłowska, J. Zubrzycki, ITM Web of Conferences. 15, 02007 (2017)

8. R. L. Drake, W. Vogl, A. W. M. Mitchell, H. Gray, Gray's anatomy for students: online access + interactive extras; studentconsult.com (Elsevier, Churchill Livingstone, Philadelphia, Pa., 2005)

9. A. A. White, M. M. Panjabi, Clinical biomechanics of the spine (Lippincott, Philadelphia, 2nd ed., 1990)

10. V. Lafage, F. Schwab, A. Patel, N. Hawkinson, J.P. Farcy, Spine. 34, E599-E606 (2009)
11. S. D. Glassman, K. Bridwell, J. R. Dimar, W. Horton, S. Berven, F. Schwab, Spine. 30, 20242029 (2005)

12. M. M. Panjabi, J. Duranceau, V. Goel, T. Oxland, K. Takata, SPINE. 16, 861-869 (1991)

13. M. M. Panjabi, K. Takata, V. Goel, D. Federico, T. Oxland, J. Duranceau, M. Krag, SPINE. 16, 888-901 (1991)

14. J. A. Waxenbaum, B. Futterman, in StatPearls (StatPearls Publishing, Treasure Island (FL), 2018; http://www.ncbi.nlm.nih.gov/books/NBK470583/)

15. J. P. Urban, J. F. McMullin, Biorheology. 22, 145157 (1985)

16. J. C. Iatridis, J. J. MacLean, M. O'Brien, I. A. F. Stokes, Spine. 32, 1493-1497 (2007)

17. F. Galbusera, M. van Rijsbergen, K. Ito, J. M. Huyghe, M. Brayda-Bruno, H.-J. Wilke, European Spine Journal (2014), doi:10.1007/s00586-0143203-4

18. M. A. Adams, D. W. McMillan, T. P. Green, P. Dolan, Spine. 21, 434-438 (1996)

19. M. F. Ivicsics, N. E. Bishop, K. Püschel, M. M. Morlock, G. Huber, Journal of Biomechanics. 47, 1712-1717 (2014)

20. A. Nachemson, Clin. Orthop. Relat. Res. 45, 107122 (1966)

21. G. M. Jensen, Phys Ther. 60, 765-773 (1980)

22. N. L. Nerurkar, D. M. Elliott, R. L. Mauck, Journal of Biomechanics. 43, 1017-1030 (2010)

23. P.-P. A. Vergroesen, I. Kingma, K. S. Emanuel, R. J. W. Hoogendoorn, T. J. Welting, B. J. van Royen, J. H. van Dieën, T. H. Smit, Osteoarthritis and Cartilage. 23, 1057-1070 (2015)

24. K. Torres, G. Staśkiewicz, M. Śnieżyński, A. Drop, R. Maciejewski, Folia Morphologica. 70, 1-4 (2011)

25. P. Gargiulo, Í. Árnadóttir, M. Gíslason, K. Edmunds, I. Ólafsson, Journal of Healthcare Engineering. 2017, 1-8 (2017)

26. M. Frame, J. S. Huntley, The Scientific World Journal. 2012, 1-7 (2012)

27. P. Potamianos, A. A. Amis, A. J. Forester, M. McGurk, M. Bircher, Proceedings of the Institution of Mechanical Engineers, Part H: Journal of Engineering in Medicine. 212, 383-393 (1998)

28. P. Gargiulo, T. Pétursson, B. Magnússon, P. Bifulco, M. Cesarelli, G. M. Izzo, G. Magnúsdóttir, G. Halldórsson, G. K. Ludvigsdóttir, J. Tribel, H. Jónsson, Artificial Organs. 37, 567-573 (2013)

29. R. Karpiński, Ł. Jaworski, J. Zubrzycki, ITM Web Conf. 15, 07015 (2017)

30. K. Falkowicz, ITM Web of Conferences. 15, 07013 (2017) 
31. R. Karpiński, Ł. Jaworski, J. Zubrzycki, Advances in Science and Technology Research Journal. 10, 240-246 (2016)

32. K. Falkowicz, Archives of Civil Engineering. 63, 161-172 (2017)

33. M. Szala, K. Beer-Lech, K. Gancarczyk, O. B. Kilic, P. Pędrak, A. Özer, A. Skic, Advances in
Science and Technology Research Journal. 11, 76-82 (2017)

34. M. Zhang, F. Pu, L. Xu, L. Zhang, J. Yao, D. Li, Y. Wang, Y. Fan, International Orthopaedics. 40, 1239-1246 (2016)

35. C. Wong, P. M. Gehrchen, T. Darvann, T. Kiaer, IEEE Transactions on Medical Imaging. 22, 742746

(2003) 